\title{
Urinary Tract Infection in Non-Hospitalized Patients With Cirrhosis and No Symptoms of Urinary Tract Infection: A Case Series Study
}

\author{
Rita de Cássia Reis Cruz ${ }^{1}$, \\ Davi Tanajura ${ }^{1}$, Delvone Almeida ${ }^{1}$, \\ Marla Cruz ${ }^{2}$ and Raymundo Paraná ${ }^{3}$
}

\author{
${ }^{1}$ Faculty of Medicine of Bahia, Brazil, Post-graduation Program in Health \\ and Medicine; ${ }^{2}$ LEME Laboratory; ${ }^{3}$ Gastro-Hepatology Unit, University \\ Hospital of Bahia, Brazil
}

Bacterial infections are important factors in decompensation, and they increase the mortality rate of patients with liver cirrhosis. The most common infections among these patients are spontaneous bacterial peritonitis, pneumonia, skin infections and urinary tract infections (UTI). This transversal study evaluated the frequency of UTI in non-hospitalized patients with cirrhosis followed in a hepatology outpatient unit. Patients with clinical, laboratorial, echographic and/or histological diagnosis of cirrhosis were evaluated from April 2002 to August 2004. Patients who accepted participating in this study were submitted to clinical evaluation and the following laboratorial examinations: urine analysis, urine culture, blood culture and hepatic function tests. Patients with symptoms of UTI, diabetis, prostatic disease were excluded. Eighty-two patients with cirrhosis were studied. Their mean age was 51 years $(\mathrm{SD}=11)$; $73 \%$ were male. Hepatitis $\mathrm{C}$ virus was the main etiology in $45 \%$ of the cases. The Child-Pugh B functional class was observed in $52 \%$ of the cases. Urine cultures were positive in $\mathbf{4 . 9 \%}$ of these patients. In this study of non-hospitalized cirrhotic patients, with no symptoms of UTI, the frequency of urinary tract infection was approximately $5 \%$. The bacteria found were $\boldsymbol{E}$. coli and Klebsiella pneumonia. We conclude that it is necessary to screen for UTI in such patients.

Key Words: Urinary tract infection, infections in cirrhotics, liver parenchyma chronic disease.

Bacterial infections are important factors in decompensation of cirrhotic patients and are found in $20 \%$ to $60 \%$ of patients at hospital admission, being associated with worsening prognosis and increased mortality rates [1]. Spontaneous bacterial peritonitis (SBP), urinary tract infection (UTI), pneumonia and skin infections are the most common infectious complications in these patients [1-7].

Patients with decompensated cirrhosis are more susceptible to infections compared to those with compensated cirrhosis, due to alterations in the immunological system [8]. Urinary tract infections account for $12 \%$ to $29 \%$ of infectious complications found in decompensated cirrhotic patients [9]. Approximately $70 \%$ to $80 \%$ of the isolated organisms are Gramnegative bacteria $[10,11]$. In recent years, the use of prophylactic antibiotics has resulted in the appearance of Grampositive infections that can be found in up to $53 \%$ of cases $[12,13]$.

In cirrhotic patients, UTI may be asymptomatic or oligosymptomatic; and asymptomatic bacteriuria is found at a high frequency $[13,14]$. The high UTI frequency in cirrhotic patients, especially in those with ascites, could be related to the residual urinary volume and possibly to the frequently found vesical dysfunction $[15,16]$.

Received on 22 May 2006; revised 18 October 2006.

Address for correspondence: Dr. Rita de Cássia Reis Cruz. Avenida Jorge Amado, Edf. Angélica, apt. 1104, Imbuí. Zip code: 41720040 - Salvador - Bahia, Brazil. Phone: (55 71) 3461-3361. E-mail: rcruz@atarde.com.br.

The Brazilian Journal of Infectious Diseases 2006;10(6):380-383. (C) 2006 by The Brazilian Journal of Infectious Diseases and Contexto Publishing. All rights reserved.
Data on UTI frequency in non-hospitalized patients and the impact of this condition on this subgroup of patients is scarce. Published studies only evaluated patients hospitalized due to bacterial infections or those who developed this complication during the hospitalization period $[17,18]$. We decided to examine the frequency and the clinical signs of urinary infection in non-hospitalized cirrhotic patients.

\section{Material and Methods}

Cirrhotic patients were selected among individuals who were being evaluated for liver transplantation from April 2002 to November 2004. The inclusion criteria were: no symptoms associated with UTI, no diabetes mellitus, no prostatic disease, no urinary litiasis, no anatomic alterations of urinary tract, no kidney graft, no immunosuppressive therapy during the previous six months, no hospitalization during the previous six months and no use of antibiotics the last two weeks before screening. A descriptive and observational transversal study was performed.

The data collection was performed through a structured questionnaire. Patients were submitted to laboratorial evaluation, including a biochemical analysis of the renal and hepatic functions, urine analysis, urine culture and blood culture.

Diagnosis of cirrhosis was based on clinical, biochemical, echographic, and hepatic biopsy data, using the Child-Pugh classification in order to determine the stage of the disease [19].

Urinary infection diagnosis was made based on laboratory data (> 10 leukocytes $/ \mathrm{mm}^{3}$ in urine and/or positive uroculture). 
The finding of numerous bacteria in the urine with no symptoms was considered asymptomatic bacteriuria [20]. A bacteremia diagnosis was considered when the patient had a positive blood culture, regardless of leukocytosis in the peripheral blood. Shortly after consultation, appropriate collectors were provided and after cleaning the external genital organs, the intermediate flush was collected for sedimentoscopy and culture.

Blood culture was performed using the HEMOBAC culture medium (Probac, São Paulo, Brazil). After being incubated at $35-37^{\circ} \mathrm{C}$, the flask was examined for growth and colonies identified. Urine culture was performed using commercial kits from Bio-Merrieux (Lyon, France). The statistical program Statistical Package for the Social Sciences was used (SPSS Chicago - IL version 9.0, 1998) was used for analyses. This research was approved by the ethics committee of our institution. The patients were included in the study after agreeing with and signing the informed consent form.

\section{Results}

Eighty-two patients were selected from among 189 cirrhotic patients evaluated in our outpatient unit. The clinical characteristics of these patients are presented in Table 1. Male gender was observed in $73 \%$ (60) of the sample. The age ranged from 24 to 79 years, with a mean age of 50.7(standard deviation $(S D)=10.9)$. A predominance of hepatitis $C$ virus was observed in the cirrhosis etiology, accounting for $45 \%(n=37)$ of the cases, followed by alcoholic etiology in $28 \%(\mathrm{n}=23)$ and hepatitis $B$ virus in $15 \%(n=12)$.

Table 2 shows relevant clinical aspects associated with cirrhosis of the patients; $42 \%(n=34)$ had a history of upper digestive hemorrhage (UDH) and $2.4 \%(\mathrm{n}=2)$ had been affected by lower digestive hemorrhage (LDH).

Ascites was found in $65 \%(n=53)$ of the cases. In $8.5 \%$ $(n=7)$ cases, SBP was reported in the medical file. A past of hepatic encephalopathy was reported in $23 \%(n=19)$.

The laboratory data for the patients and their division into groups with and without UTI are given in Table 3. When we grouped the patients according to Child-Pugh criteria (Table 4), there was a predominance of patients in group B 52\% $(n=43)$; we also found $35.4 \%(n=29)$ in group $A$ and $12 \%(n=10)$ in group C (Table 4).

UTI was diagnosed by urine culture in four (4.9\%) patients. In all four cases, urine analysis showed increased leukocyte counts. No gender differences were observed for UTI frequency (two male patients and two female patients). The mean age was $56.2 \pm 15.1$ years. One patient presented hepatitis $B$ virus, another patient had no defined etiological diagnosis and two patients presented alcoholic etiology for cirrhosis (Table 1). Among the patients who had UTI, one presented upper digestive bleeding in the past, three patients presented ascites and one presented a past of hepatic encephalopathy
(Table 2). All of them reported at least one complication of liver cirrhosis.

Escherichia coli was found in three patients and Klebsiella pneumonia in one patient. After urinary tract infection was identified, the patient received adequate orientation for treatment or was hospitalized and treated.

\section{Discussion}

The frequency of asymptomatic bacteriuria in nonhospitalized patients with cirrhosis and no predisposing condition for UTI was $4.9 \%$. All patients with UTI reported complications in the past. All patients presented positive uroculture and leukocyturia in the urine analysis. This frequency of UTI cannot be considered low. Taking into consideration the severe exclusion and inclusion criteria and the fact that only non-hospitalized patients with no urinary symptoms were selected, $4.9 \%$ UTI prevalence points to a need for systematically screening urine analysis in such patients.

There have been few published studies on urinary tract infections in non-hospitalized patients with cirrhosis followed in outpatient units. These studies were made on decompensated patients who needed hospitalization or on patients who acquired their UTI during the hospital internment period $[4,8,9,12,20]$. In some papers, information on patients was not reported, and important details, such as death rates and associated diseases (diabetes mellitus, renal dysfunctions) were neglected.

Among nearly all studies, the frequency of UTI ranged from $2.1 \%$ (3/140) to $33.6 \%$ (111/330); in a single study [21] a frequency of $68 \%$ (68/100) was found, probably due to the large proportion of women.

Escherichia coli was common in the urine culture of our patients; this finding was similar to findings of other authors, despite the low number of patients with UTI in our study.

In conclusion, we found approximately 5\% UTI among non-hospitalized cirrhotic patients with no urinary symptoms and/or predisposing conditions to UTI. Other studies of infections in cirrhotic patients have been made [22], but our study points to the clinical importance of this particular topic. Further studies would be useful to evaluate clinical aspects associated with susceptibility to this type of infection.

\section{References}

1. Clay W., Strauss E. A prospective study of bacterial infections in patients with cirrhosis. J Hepatol 1993; 18:353-8.

2. Wike R.J. Susceptibility to infection in liver disease. Current Opinion Gastroenterology 1986;2:471-7.

3. Wyke R. Problems of bacterial infection in patients with liver disease. Gut 1987;28:623-41.

4. Cadranel J.F., Denis J., Pauwels A., et al. Prevalence and risk factors of bacteriuria in cirrhotic patients: a prospective casecontrol multicenter study in 244 patients. J Hepatol 1999;31:464-8. 
Table 1. Demographic characteristics and etiology of cirrhosis among outpatients

\begin{tabular}{lccr}
\hline & With UTI(\%) & Without UTI $(\%)$ & Total $(\%)$ \\
\hline $\begin{array}{l}\text { Gender } \\
\quad \text { Male }\end{array}$ & $58(74.4)$ & $2(50.0)$ & $60(73.2)$ \\
$\quad$ Female & $20(25.6)$ & $2(50.0)$ & $22(26.8)$ \\
Age & & & \\
Etiology & $50.41 \pm 10.71$ & $56.25 \pm 15.15$ & $50.70 \pm 10.92$ \\
$\quad$ Alcohol & $21(26.9)$ & $2(50.0)$ & $23(28.0)$ \\
$\quad$ Virus B & $11(14.1)$ & $1(25.0)$ & $12(14.6)$ \\
$\quad$ Virus C & $37(47.4)$ & 0 & $37(45.1)$ \\
$\quad$ Others & $9(11.5)$ & $1(25.0)$ & $10(12.2)$ \\
\hline
\end{tabular}

Table 2. Clinical aspects associated with cirrhosis among outpatients

\begin{tabular}{lccc}
\hline & Without UTIn(\%) & With UTIn(\%) & Total n (\%) \\
\hline UDH in the past & $33(42.3)$ & $1(25.0)$ & $34(41.5)$ \\
LDH in the past & $2(2.6)$ & 0 & $2(2.4)$ \\
Ascites & $50(64.1)$ & $3(75.0)$ & $53(64.6)$ \\
SPB in the past & $7(9.0)$ & 0 & $7(8.5)$ \\
HE in the past & $18(23.1)$ & $1(25.0)$ & $19(23.2)$ \\
\hline
\end{tabular}

UDH - upper digestive hemorrhage; LDH - low digestive hemorrhage; SBP - spontaneous bacterial infection; HE hepatic encephalopathy.

Table 3. Clinical aspects associated with cirrhosis among out patients

\begin{tabular}{lccc}
\hline & Without UTI & With UTI & Total \\
\hline Total protein & $7.19 \pm 0.68$ & $6.5 \pm 0.52$ & $7.16 \pm 0.69$ \\
Albumin & $3.45 \pm 0.64$ & $3.3 \pm 0.78$ & $3.46 \pm 0.64$ \\
Prothrombin time & $63.58 \pm 17.09$ & $65.5 \pm 15.67$ & $63.67 \pm 16.94$ \\
Total bilirubin & $2.0 \pm 1.5$ & $1.72 \pm 1.2$ & $1.99 \pm 1.57$ \\
Conjugated bilirubin & $0.89 \pm 1.14$ & $0.74 \pm 0.49$ & $0.88 \pm 1.11$ \\
Blood glucose level & $87.2 \pm 11.04$ & $83.25 \pm 3.86$ & $87.2 \pm 10.82$ \\
\hline
\end{tabular}

Table 4. Classification of cirrhosis in outpatients according to Child-Pugh criteria

\begin{tabular}{cccc}
\hline & Without UTIn(\%) & With UTIn(\%) & Total n(\%) \\
\hline A & $28(35.9)$ & $1(25.0)$ & $29(35.4)$ \\
B & $41(52.6)$ & $2(50.0)$ & $43(52.4)$ \\
C & $9(11.5)$ & $1(25.0)$ & $10(12.2)$ \\
\hline
\end{tabular}

5. Deschênes M., Villeneuve J.P. Risk factors for the development of bacterial infections in hospitalized patients with cirrhosis. Am J Gastroenterol 1999;94:2193-7.

6. Borzio M., Salerno F., Piantoni L., et al. Bacterial infection in patients with advanced cirrhosis: a multicentre prospective study. Dig Liver Dis 2001;33:41-8.

7. Strauss \& Aerosa J.P. Infecções bacterianas pioram o prognóstico da hepatite alcohólica. Rev Soc Bras Med Trop 2004;37:198-203.

8. Navasa M., Fernández J., Rodés J. Bacterial infections in liver cirrhosis. Italian J Gastroenterol Hepatol 1999;31:616-25.
9. Navasa M., Rimola A., Rodés J. Bacterial infections in liver disease. Semin Liver Dis 1997; 17:323-33.

10. Rosa H., Silverio A.O., Perini R.F., et al. Bacterial infection in cirrhotic patients and its relationship with alcohol. Am J Gastroenterol 2000;95:1290-3.

11. Campillo B., Dupeyron C., Richardet J.P., et al. Epidemiology of severe hospital-acquired infections in patients with liver cirrhosis: effect of long-term administration of norfloxacin. Clin Infec Dis 1998;26:1066-70.

12. Fernández J., Navasa M., Gomez J., et al. Bacterial infections in cirrhosis: epidemiological Changes with invasive procedures and norfloxacin prophylaxis. Hepatology 2002;35:140-8. 
13. Burroughs A.K., Rosenstein I.J., Epstein O., et al. Bacteriuria and primary biliary cirrhosis. Gut 1984;25:133-7.

14. Lipsky B.A. Urinary tract infections in men. Epidemiology, pathophysiology, diagnosis, and treatment. Ann Intern Med 1989; $110: 138-50$.

15. Rimola A., Soto R., Bory F., et al. Reticuloendothelial system phagocytic activity in cirrhosis and its relation to bacterial infections and prognosis. Hepatology 1984; 4 :53-8.

16. Bercoff E., Frebourg T., Sennant J., et al. Urinary tract infection in cirrhotic patients, a urodynamic explanation. Lancet 1985;1(8435):987.

17. Navasa M., Rodés J. Bacterial infections in cirrhosis. Liver Intern 2004;24:277-80.
18. Pugh R.N., Murray-Lyon I.M., Dawson J.L., et al. Transection of the oesophagus for bleeding oesophageal varices. British J Surg 1973;60:646-9.

19. Sobel D.J., Kaye D. Urinary tract infections. In: Mendell GL, Benner JE, Dolin R, eds. Principles and practice of infectious disease. 4 edition, New York: Churchill Livingstone 1995;662-90.

20. Toledo C., Flores C., Saenz M., et al. Infecciones bacterianas en la cirrosis hepática. Rev Med Chile 1994;122:788-94.

21. Cabrejos O., Lozano A.M., Vargas G.C. Infecciones intercurrentes en pacientes cirróticos en el hospital Arzobispo Loayza. Rev Gastroenterol Peru 2000;20:146-51.

22. Frazee L.A., Marinos A.E., Ryharczyk A.M., et al. Long-term prophylaxis of spontaneous bacterial peritonitis in patients with cirrhosis. Ann Pharmacother 2005;39:908-12. 